\title{
PARTICIPIO DE PRESENTE LATINO TARDÍO Y MEDIEVAL: ENTRE NORMA Y HABLA*
}

\author{
JUAN FCO. MESA SANZ \\ Universidad de Alicante \\ juan.mesa@ua.es
}

\begin{abstract}
Resumen
The use of present participle in the literary texts and its problems of translation to a romanic language manifest the syntactical devclopment of that verbal form; in the same way, they show the tension from its double nature: verbal and adjectival. That tension was broken in the Late and Medieval Latin: while the development «vulgar», actual germ for the romanic languages, marked the adjectival, at the same time in literary texts was used as verbal form, even as predicate. That use has been called «written vulgarism». It was its origin in the literary spoken properly, cause of the great productivity and economy as expresive tool. Nevertheless, latest centuries of Empire knew a group of phacnomena that acelerated theses verbal uses. First at all, the school into a environment of poor culture caused that «syntactic hypercorrection», an actual «scholar vulgarism», born in the sermo scolasticus.
\end{abstract}

\section{Entre la naturaleza verbal y la nat uraleza adjetiva}

Uno de los escollos que debe superar el aprendiz de traductor de la lengua latina es la correcta interpretación de las estructuras de participio, muy abundantes en algunos autores. Evidentemente éste no está motivado por el hecho de que, adquirida cierta soltura y hábito con los textos latinos, sean estructuras especialmente complejas, sino, más bien, debido a la dificultad de discernir cabalmente cuál de sus dos naturalezas, verbal o nominal ${ }^{1}$, debe primar en nuestra interpretación, a cuál de las dos podrá renunciar el traductor sin que cste hecho suponga una alteración grave del sentido quc el autor original queria transmitimos ${ }^{2} ; \mathrm{y}$, sobrc todo, en el plano docente, la estructura participial se ha resistido a toda simplificación normativa que no conllevara el riesgo de incurrir en un falseamiento de la realidad de la lengua. Veamos un ejemplo gracias a un fragmento de Suelonio:

\footnotetext{
* Proyecto emergente Corpus Documentale Latinum Valentiae (Financiación de Proyectos de Investigación Emergentes; Vicerrectorado de Investigación de la Universidad de Alicante GR-12).

1 Serbat, 1985.

2 Concurren en esta forma verbal problemas para todas la reglas que, en palabras de Etienne Dolet, La manière de bien traduire d'une langue en autre, dcbcn cumplirse para evitar una traducción literal: kel traductor debe entender el sentido del tcxto y la materia del mismo; debe conocer las dos lenguas que se comparan; debe atender sobre todo a la intención del autor; $\mathrm{y}$, finalmente, evitar el cullismo y atenerse a la norma linguística de la lengua de destino (cit. en: Vega, 1994: 34).
} 
Cunctanti ostentum tale factum est. Quidam eximia magnitudine et forma in proximo sedens repente apparuit harundine canens (SUEtonio, XII Vitae Caesarum, Diuns Iulius, 32)

Vacilaba todavía, cuando le sobrcvino un prodigio. Un hombre de estatura y belleza extraordinarias aparceio de repente y sentándose a poca distancia se puso a tocar la flauta (trad. Bassols, 1964).

Ante sus dudas, se le ofreció la siguiente señal prodigiosa. Un hombre de extraordinaria estatura y belleza apareció de repente, sentado en un lugar cercano, tocando una flauta (trad. Agudo, 1992).

Como puede observarse, ya que lo hemos señalado en negrita, el texto latino presenta tres participios de presente: cunctanti, sedens y canens. Bassols opta en su traducción por convertir estos participios en formas personales del verbo o en gerundio; e incluso procede a la alteración de la relación sintáctica entre las formas verbales: cunctanti (forma dependiente) se convierte en vacilaba (verbo principal, que arrastra a la subordinación al verbo principal en la estructura latina); cantens (forma dependiente) traducido y ... se puso a tocar.. (verbo principal) sc construye en condiciones de igualdad con el único verbo principal en el texto latino, apparuit, y provoca el cambio de dependencias en la oración, puesto que sentándose es un gerundio dependientc de se pone a tocar y no de apareció como la dependencia de sedens con respecto a appartit reclama. En la segunda de las traducciones, en cambio, Agudo ha sido mucho más respetuosa con la sintaxis latina, dado que mantiene las dependencias originales: así cunctanti es reproducido por medio de un complemento circunstancial, ante sus dudas - a la vez que el caso dativo es reflejado en ambas traducciones por medio del pronombre le-; sedens es traducido por el participio español sentado; y canens por el gerundio tocando. Es decir, aun respetando la estructura del texto latino, la necesaria adaptación a la lengua española ha propiciado el empleo de tres estructuras diferentes $y$, obsérvese, la única que mantiene exactamente la misma función es sentado (<sedens) y, en ella, cabe la posibilidad de preguntarnos por qué Suetonio no emplé sessus (participio de perfecto) si quería expresar que la acción de «sentarse» por parte de ese misterioso personaje ya había sido concluida y no que mientras tocaba se sentaba", lo que sensu stricto y gramática latina en mano afirmaríamos ${ }^{3}$.

El único modo de reflejar en plenitud (y no siempre) la estructura latina sería utilizar una «cultista y latinizante» traducción como la siguiente:

*Al vacilante se le manifesló el siguiente prodigio. Uno de extraordinaria estatura y belleza, sedente en un lugar cercano, apareció súbitamente tocante una flauta.

3 Aunque no abundaremos en ellos a lo largo del presente trabajo, la realidad de la lengua presenta interferencias que una gramática estructural sencilla no es capaz de observar. En este caso lo seria de carácter semántico, ya que en los textos conservados el nominativo singular del participio perfeclo, sessus, no fue empleado, lo que elimina la oposición sedens/sessus. Los usos en otros casos sc limitan a tres apariciones: cum autem ad Laceducmonios accessisset, qui legati cum essent, certo in loco consederant, consurrexisse onmes illi dicuntur et senem sessum recepisse (Cicerón, Cato Maior 63); nam cui paratumst quod edit, nostra gratia nimia est stultitia sessum impransum incedere (Plauto, Poenuhs 10); scortum exoletwm ne ouis in proscaenio sedeat, nea lictor verbum aut virgae muttiant, net dissignator praeter os obambulet net sessum ducat, dum histrio in scaena siet. (ibid. 20). Sedens, -ntis, por el contrario, presenta más de 500 apariciones. Las búsqucdas han sido realizadas en el Thesaurus linguae Latinae del Packard Humanities Institute. 
El extrañamiento que se produce cs notable, por más que los adjetivos en -nte estén reconocidos en la lengua española: (i) sedente sólo en calidad de adjetivo; (ii) tocante como «participio activo» (sic) ${ }^{4}$ y como elemento de la locución adverbial tocante a, y (iii) vacilante también como participio activo por Julio Casares ${ }^{5}$. Por ello puede dudarse sobre su gramaticalidad - siempre cultista - o no, cuando no poseen régimen; cuando lo tienen, la construcción es ajena a las utilizadas en lengua española.

En consecuencia, son patentes la falta de adecuación entre los paradigmas de las dos lenguas ${ }^{6}$ y una cierta sensación de arbitrariedad - compensada por la «competencia» del traductor- entre las diferentes posibilidades de traducción. Si bien la primera no tiene solución, para tratar de minimizar la segunda puede recurrirse a aplicar la más tradicional definición de participio?: «Son formas que, como su nombre indica, participan a la vez de la naturaleza de los adjetivos y de los verbos». De acuerdo con ella y en la ausencia de un participio adecuado en español las posibilidades de traducción son varias:

\section{Por su naturaleza adjetiva:}

A él, que vacilaba, se le manifestô el siguiente prodigio. Uno de extraordinaria cstatura $y$ belleza, que estaba sentado en un lugar cercano $y^{8}$ que tocaba una flauta, apareció súbitamentc.

Por su naturaleza verbal:

Mientras vacilaba, sc le manifestó el siguiente prodigio. Uno de extraordinaria estatura y belleza, sentándose en un lugar cercano, apareció súbitamente tocando una flauta.

Y lo más adecuado, por supuesto, será combinar las diferentes posibilidades:

Mientras vacilaba, se le manifestó el siguiente prodigio. Uno de extraordinaria estatura y belleza, que estaba sentado en un lugar cercano, apareció súbitamente tocando una flauta.

\footnotetext{
$4 \mathrm{XXI}^{\mathrm{a}}$ edición del diccionario. En la XXIª se deja de emplear esta denominación, salvo con lines etimológicos; otro tanto sucede en Seco-Andrés- Ramos, 1999.

5 Fernández Murga (1975:364) afirma, citando a Gili (1964: 203), que «La Academia española enumera los siguientes participios de presente usados en función de talcs: abundante, bullente, complaciente, concerniente, condescendiente, conducente, conveniente, correspondiente, crujiente, equivalente, fascinante, obediente, participante, pernanente, plasmante, presente, recurrente, tocante. A ellos habría que añadir ausente, demandante, querellante, firmante, solicitante y algunos más. Pero téngase en cucnta que aún los participios mencionados se emplean ordinariamente como adjetivos». Así, cn efecto, no tienen consideración de forma verbal en los estudios más recientes, desde R.A.E. (1983), hasta Bosque - Demotte (1999), pasando por $\Lambda$ larcos (1994); éstos, si espigamos entre sus afirmaciones y la exposición de las estructuras adjetivas, parten de un reconocimiento de toda una subcategoría adjetiva procedente de los participios de presente latinos, pero no de una categoría propiamente verbal.

6 La forma de participio castellana supone un resto exiguo - que se corresponde con cl participio de perfecto o pasado - de lo que en latín era un usistema imperfecto" de cuatro formas de adjetivo verbal; decimos imperfecto porque no poseía una forma para cada uno de los cuadrantes del esquema estructural en el que se cruzan los tres tiempos (presente, pasado y futuro) con las dos voces (activa y pasiva), muy al contrario de lo que, por cjcmplo, sucedía en griego, que conpleta el cuadro y aún lo amplia hasta diez formas con la inclusión del aoristo y la voz media.

7 Bassols, 1956: I, 365.

8 Obsérvese que se impone la necesidad de ineluir una coordinación (i.e. nos confirma la difctcncia funcional entre los dos participios).
} 
Por consiguiente, frente a un concepción de partida de carácter morfológico que considera a los tres participios de presente iguales, proponiendo divergencias que han de asociarse a la función sintáctica (cunctanti y sedens / canens, ya que canens no es sólo determinante), al orden de palabras (sedens / canens, puesto que, referidos al mismo sustantivo, sólo cl orden de palabras cxplica su diferente interpretación, así como la ausencia de coordinación entre ellos) o la semántica de los términos (sedens / cunctanti y canens, oposición de carácter semántico $^{9}$ ). Los trabajos de lingüística latina rara vez han atendido a los dos últimos factores $^{10}$, más bien ha destinado sus esfuerzos a una clasificación de las funciones desempeñadas por los participios en la oración.

La función más simple es aquella en la que se identifica al participio como un adjetivo, la de atributo": Videtis ut senectus sit operosa et semper agens aliquid (Cicerón, De senectute V, 115). Dentro de esta función se puede localizar lo que Lavency (1997: 190-199) denomina «epíteto» y puede sustituirse por proposición relativa: Lex recta ratio imperans honesta, prohibens contraria (Cicerón, In Antonium II, 25); y los participios sustantivados o nominalizados ${ }^{12}$ : Audentes fortuna iuuat (Virgilio, Eneida X, 284) ${ }^{13}$.

Mayor complejidad tiene la presencia de los participios en función predicativo (Pinkster, 1995: 193-195), es decir, cuando es un constituyente que puede omitirse sin que el resto de la oración sc convicrta en agramatical, sin que se altere, por tanto, la estructura sintáctica ni la semántica: rex ... in foro, inquam, Syracusis flens ac deos hominesque contestans clamare coepit (Cicerón, In Verrem IV, 67). Es una estructura que se enriquecerá y complicará con el paso del tiempo, debido a la productividad literaria que posee, siendo Cicerón el autor que inicia su auténtica explotación ${ }^{14}$ (Laughton, 1964). A esta categoría, participium coniunc$t u m^{15}$, pertenecen todas las estructuras de participio que se consideran equivalentes a proposiciones adverbiales, principalmente temporales, mas igualmentc causalcs, condicionales, concesivas o finales ${ }^{16}$, sin que parezca evidente la oposición entre unas y otras. Incluso apa-

\section{Vide nota 2.}

10 El orden de palabras en la lengua latina, evidenciado por Marouzeau (1922) con fines estilisticos - valor «emotivo»-y preexistentes en las gramáticas antiguas (Luque, 1978), posee unas tendencias expuestas por Rubio (1972) y aplicadas a diversos autores y fenómenos de la lengna por otros autores. No existe ningún estudio dedicado al orden de palabras del participio latino y no han faltado voces discrepantes contra la tesis tradicional (e.g. Lehmann, 1973 y Pinkster, 1995). En suma, la imposibilidad de establecer una tipología completa del orden de palabras latino contribuye a que siga siendo válida la tesis de Kühner - Stegmann (1912-1914: Il, 590), según la cual debemos contentarnos con cxplicar por qué se escoge un orden concreto en casos específicos. Fn lo que respecta a las interferencias entre la sintaxis y la semántica, aunque no existe ningún trabajo especifico sobre los participios, Pinkster (1995) ha consagrado la «etiqueta» participio dominante para estructuras del tipo occisus dictator ... pulcherrinum facinus uidebatur (Tácito, Annales $\mathbf{I}, 8,6$ ).

11 Vide igualmantc Kühner - Stcgmann (1912-1914: II, 755-798); Bassols (1956: I, 365-386); Serbal et alii (1994: 286-302).

12 Adams, 1973.

13 Woodcock $(1959,77-83)$.

14 En buena medida, esta ampliación en el uso es debida a la influencia de la lengua griega (Marouzeau, 1910 ).

15 Pinkster (1995: 185-186); Woodcock (1959: 72-77) incluye también la construcción absoluta.

16 Algunos ejemplos son: lemporal, Lacias Pelrosidius aquilifer ... pro castris foritssime pugnans occiditur (César, De bello Gallico V, 37, 5); causal, C. Seruilius Ahala Spurium Macium regnum appetentem ... interemil (Ciccrón, De senectute 56); condicional, idem traducti a disputando ad dicendum inopes reperiantur (Cicerón, Brutus 118); concesivo, et quae iam diu gesta et a memoria nostra remota tamen faciant fidem uere tradita esse (Cicerón, De imuentione I, 39); o final, quam penterse fugiens Hegesias ... saltat incidens panticulas (Cicerón, Orator 226). Mensick, 1994. 
recen en los textos estructuras sustantivas en oposición a las cstructuras de infinitivo: idque Socratem ... audio dicentem (Cicerón, De finibus II, 90) / idque Socratem audio dicere ${ }^{17}$; o de carácter complementario: Homerus ... Laertem ... colentem agrum ... facit (Cicerón, De senectute 54) / Homerus Laertem colere agrum facit ${ }^{18}$.

Finalmentc, todas las gramáticas coinciden en señalar la existencia del llamado «participio dominante» o estructura «ab Vrbe condita» que sustituyc a un nombre verbal con complemento y conmuta con un pronombre neutro: fugiens ... Pompeius ... homines monet (Cicerón, Ad Atticum VII, 11, 4) ${ }^{19}$; del participio absoluto ${ }^{20}$. Nullo hoste prohibente aut iter demorante, incolumen legionem in Nantuantes perduxit (Caesar, de bello Gallico III, 6, 5); y de las perífrasis vcrbales: ego sum Ioui dicto audiens (Plauto, Amphitruo 989) ${ }^{21}$.

La conclusión a la que apunta la tipología que hemos esbozado es que los problemas de traducción con los que hemos iniciado nuestra exposición se focalizan en el participium coniunctum. La riqueza de las formas participialcs y su mayor expresividad - junto con la influencia de la literatura griega - propiciaron la utilización creciente de estas estructuras en los textos escritos, donde faltan en lengua española ${ }^{22}$. De hecho, debemos subrayar el carácter escrito (i.e. literario) para el amplio uso del participio de presente latino, puesto que tanto cl latín vulgar como, sobre todo, las lenguas romances demuestran que pronto retornó el sufijo $-n t$ a desempeñar la función de transcategorizador nominal a partir de una base léxica verbal ${ }^{23}$ y sus usos «verbales» fueron sustituidos por proposiciones subordinadas o por el ablativo del gerundio - origen del gerundio romance-.

17 Esta oposición cstá restringida a los verbos de percepción y se ha indicado que en las estructuras $\Lambda \mathrm{cP}$ el aspecto fundamental es el de la "percepción», mienlras que en las AcI, lo es el de «conocimiento y reflcxión»" (Pinkster, 1995: 167-168, citando principalmente a Bolkestein (1976)).

18 La estructura facio + AcI es causativa, como muestra el Th.L.L., s.v. facio, «cum is, qui facit, non tantum causa rei ucl fabricator, sed auctor est, facere assumit notionem iubendis. En cambio, la estructura con participio debe distinguirse de tal valor como afima Pinkster (1995: 194, n. 26) a partir de la indicación de Heinc (1990:6-7).

19 Pinkster (1995: 168-171); Lavency (1997: 190-199).

20 Iavency (1997) dcfinc esta estructura como una «proposición subordinada constituida por un sustantivo en ablativo y un participio o un atributo en ablativo; funciona el sintagma como complemento de la oración y describe la situación concomitante con el proceso expresado en la principal. Su supresión mantendría la gramaticalidad\%. En nuestra opinión no hay nada que las haga especiales frentc al participio dominante y el coniunctum, salvo, por supucsto, su frceucncia de uso. Vide Coleman, 1989, y Ramat, 1994.

21 Estos dos últimos párrafos son catalogados por Ernoul - Thomas (1953: 273-283) bajo el epigrafe «Construcciones participiales", donde se incluyen el (i) part. pres. / pas. = sustantivo verbal o análogo abstracto; (ii) part. por inf. o proposición sustantiva; (iii) part. concertado o absoluto por proposición circunstancial. En estos últimos indican que incluso en época clásica e imperial se utilizarán partículas, e.g. (C'acsar) quamquam obsidiones Massiliae ... retardante, brevi tamen ommia subegil (Suetonio, Div Iul. 34, 4).

22 El proceso fue sinilar de la lengua griega a la latina, pucsto quc, como hemos anticipado, son más las formas de participio en griego que en latín (Zeegers - Vorst, 1997).

23 Los diversos sufijos adjetivales que conocen las lenguas indoeuropeas, de entre los que *-itt es panindoeuropeo, slo único que indicaban era que el nombre que determinaban estaba modificado, afectado, por la idea de su propia raíz: sextus era el hijo afectado por la noción de «seis» (cl nacido en sexto lugar), amatus alguien afectado por la idea de «amar» - Una lcy estadística hace que, a partir de aquí, se tendiera al tiempo pasado y a la voz pasiva: esa afección es normalmente transitiva y así de amare aliquem nace amaius (ab aliquo), amado antes de ahora por alguno-D (Adrados, 1975; 745). Mellet et alii (1994: 3001-301) concluyen que cs simplemente un clasificador sintáclico que, a partir de un tema preexistente permite formar un adjetivo; el adjetivo resultante se comportará como tal en la oración y está desprovisto de los valores temporales, aspectuales y diatéticos que tradicionalmente se le han aplicado y que son debidos al resto de los elementos lingüisticos y extralingüísticos con los quc se asocia: Es la base verbal, gracias a los afijos de infectum, la que posee los semas puntual, durativo, iterativo, etc. y es el contexto, donde el receptor y su realidad cxtralinguística también participan en el proceso, quienes contribuyen a la interpretación final de la forma del participio. 
Ahora bien, la mencionada productividad de estas formas verbales propició que las nacientes literaturas romances, por influjo de los textos latinos rccuperados en el Renacimiento rcalizasen el esfuerco de recuperarlas, cuando menos para su uso literario. Como ha mostrado Fernández Murga (1975: 360-361) los autores hispanos no aplicaron a la tarca el mismo empeño que los italianos:

\begin{tabular}{|c|c|c|}
\hline Cicerón, De inuentione $\mathbf{~}, 1$ & Brunetto Latini & Alfonso de Cartagena \\
\hline $\begin{array}{c}\text { ac me quidem diu cogitantem } \\
\text { ratio ipsa in hancpotissimum } \\
\text { sententiam ducit. }\end{array}$ & $\begin{array}{l}\text { esì me lungamente } \\
\text { pensante la ragione } \\
\text { stessa mi mena in questa } \\
\text { fermissima sentenza. }\end{array}$ & $\begin{array}{l}\text { e pensando yo luengamente } \\
\text { en esto, la razón me traxo } \\
\text { en una tal conclusión }\end{array}$ \\
\hline
\end{tabular}

Por ello, mientras la lengua de Dante recuperó el uso literario del participio de presente ${ }^{24}$ no ha sucedido los mismo en la lengua española, por más que no falten los ejemplos de uso, algunos de ellos del propio siglo $\mathrm{XX}^{25}$ :

- oh vos dubitantes creed las estorias y querría ser demandante / guardante su cirimonia, / si el puerco de Calidonia / se mostró tan admirante (Marqués de Santillana)

- Durante el rey aquella vez en Sevilla, fueron fechos muchos juegos de cañas (Gutierre Díaz de (Games)

- E cumpliendo el rey treze años, entrante en los catorze años, cntrcgáronle su reyno (Gutierre Díaz de Games)

- Los ojos ardientes, le mostró el furor de su pccho (San Juan de la Cruz)

- Declinante un día de marzo, cortan la campiña del Panadés ... y desembocan en la Plana, llamcantes los ocres de la costa sobre el agua azul (Manuel Azaña, La velada en Benicarló)

- Orillas que han vuelto florecer, turnante junio (Jorge Guillén)

El participio de presente, por tanto, sc presenta al historiador de la lengua como un ejemplo manifiesto de las divergencias existentes entre norma culta y habla, entre el uso que de la lengua hacen sus más conspicuos usuarios y cl habitual. A partir de un núcleo

24 Pese a que algunes gramáticas afirmen que «(..) si usa anche come forma verbale, (...)» (Battaglia, 1974: 288), mayoritariamente se le considera «Estraneo al parliato quotidiano, quest’uso ricorre soprattutto nella lingua giuridica e burocratica (...), ma anche nella lingua lettcraria» (Scrianni, 1997: XII 413), que, la primera, «(..) si compiace spesso di un tonoricercato e perfino aulico» (Dardano - Trifone, 1985: 245). Desde una perspectiva diacrónica, «Los parlicipios y los gerundios tienen usos más numerosos [en el 300 ] que en el doscientos y que en el quinicntos y su utilización estilística es a veces muy notablen (Alcántara, 1969: I 320), mientras en el cuatrocientos comparte espacio con otras múltiples influcncias de la lengua latina (ibidem: $I$, 404), para definitivamente en el siglo XIX «El participio presente con pleno valor verbal es muy raro y suena a literario (...) o a burocrático» (ibidem: II, 277).

25 Incluso se han levantado voces reclamando su recuperación, como la de Julio Casares (cit. Fernández Murga, 1997: 363): «'Tengo por muy dichosa innovación cl uso de los participios activos, ya que el olvido de ellos no sólo priva a la lengua de una utilísima y vigorosa forma verbal, sino que deja libre el campo al abusivo, impropio y bárbaro empleo del gerundio». «Bien sé, y es grande lástima que no hemos de recuperar el verdadero participio con su régimen verbal: temientes a Dios (Villena), centauros trayenies armas (Alfonso de la Torre), creyentes en don Christo (Berceo)... Pcro siquiera como adjetivos verbales, ¿qué enorme caudal de voces no ganariamos si las plumas cultas y autorizadas formasen los participios en -ante y -ente de los verbos que lo permiten, y los echasen a rodar por el mundo? ¿Quién no advierte al aumento de vida y energía que hay de sonoro a sonante, de verde a verdeante, de risueño a riente?» 
común, el sufijo — nt permite la formación de adjetivos a partir de verbos-, cl hablante común ancla las formas en su naturalcza adjetiva, mientras que el autor literario se sirve de la base léxica verbal en aras de ganar fuerza expresiva. Este fenómeno se produjo en lengua latina --en los periodos clásico y postclásico-, mas también se conoció en las lenguas romances desde el Renacimiento, con mayor o menor éxito, como hemos visto. Ahora bien, el ejemplo de Suetonio con el que comenzábamos subraya que la lengua latina llegó más allá: en ese aumento de la expresividad, de la capacidad de comunicación en poco espacio por medio de la utilización del participio de presente, éste terminó por emplearse de modo hasta diríamos que abusivo - un aspecto más que infiuye en los problemas de traducción que referíamos-. Y esta «hipettrofia» de un elemento de la lengua propiciaría un uso contrario al origen de estas formas por medio de la explotación de su naturaleza verbal, del uso del participio de presente en calidad de predicado de una oración o proposición en los periodos tardío y medieval.

\section{El uso taRDío (TAL VEZ VULGaR) Y MEDIEVAL DEL PARTICIPIO DF PRESENTE}

Hofmann - Szantyr (1965: 389-390) reconoce que el participio de presente es utilizado a partir del siglo III d.C. como (i) predicado principal único de la oración, Zeno itaque recompensans beneficis Theodericum ... donans ei multum et mittens eum ad Italiam (Anon. Vales. 11, 49); (ii) predicado único de proposiciones de relativo (Innocentius, qui deprecans sanctum Andream ..., ut (Inscr. Christ. Diehl 3859)), adverbiales de diverso tipo (quia ... Zenonem metuentes, ne ... (Anon. Vales. 9, 43)) e incluso, aunque raro, sustantivas (nunc quid facientes ... ignoramus (CIL IX 2437, 5)); y (iii) en coordinación con un verbo en forma personal, volentes ... esse in convivio ..., sed excluduntur (Epiphan. in evang. 32).

Estos usos, claramente agramaticales desde la norma clásica, por la abundancia de su aparición han merecido la atención de los estudiosos ${ }^{26}$. En todos ellos existe unanimidad a la hora de asociar la extensión de este uso a la influencia del griego bíblico, puesto que su traducción al latín no encontraba otra forma que facilitase la traducción del participio de aoristo griego. Este hecho posibilitaba adcmás la pérdida del sentimiento de expresión de ticmpo «presente o simultáneo» por parte del participio latino.

En las traducciones de la Biblia se produjo, en palabras de Arias (1999: 197-200) un uso «amontonado», gramatical, pero que constituía un defecto en la claridad expositiva (Bonnett, 1890: 649), que indefectiblemente condujo a estos «usos agramaticales». Una vez producidos, mantendrán una cierta tendencia de género literario, si tenemos en cuenta que preferentemente son localizados en obras historiográficas, quc con poca ambición literaria, atendiendo a su contenido histórico, consistían en simples recopilaciones de hechos -y el papel del participio para su exposición era innegable - - ${ }^{27}$. Lorcnzo (1998: 41) muestra cómo se ha producido este paso por medio de ejemplos extraídos de la historiografia, en concreto, por ejemplo, entre Orosio y Jordanes:

26 De entre todos, el trabajo más exhaustivo ha sido el realizado por Eklund (1973), cuyas conclusiones son recogidas y discutidas en Lorenzo (1998) y Arias (1999).

27 Lorenzo, 1998: 40. 
Alexander apud Babyloniam cum ... ministri insidiis venenum polasset, ineriit (Orosio III, 20)

Alexander apud Babyloniam ministri insidiis potans interitum (Jordanes, Getica X, 66)

Sin embargo, la extensión de estas construcciones participiales indican que la influencia helénica catalizó una tendencia que ya había aparccido en la lengua escrita ${ }^{28}$ como hemos visto. Abunda en este hecho la existencia de otras posibles razones para la extensión de estas estructuras. Al margen de cuestiones crítico textuales que se han argumentado en ocasiones $^{29}$, la primera tiene que ver con la tendencia «vulgar» a evitar las estructuras de la subordinación; así, las estructuras participiales aparecen en lugar de proposiciones relativas, omnis, qui dimittit uxorem suam et mubens aliam, moechatur (Vetus Latina (cod. d) Luc. 16, 18), y aumcnta el uso de participium coniunctum. La segunda de las razones es la extensión que entre los autores eclesiásticos alcanza la perifrasis, ya conocida en cl pcriodo arcaico, de participio de presente + sum; la elipsis del verbo auxiliar explicaría la aparición del participio en función de predicado. Por último, se ha subrayado su relación con el nominativo absoluto o nominativus pendens del tipo stantes ad orationem et orantes intente, surrexil mortuus ille (Vit. patr. V, 14, 17). Tal vez por la acusada influencia que en esta época la lengua hablada y familiar ejercía en la literaria, determinados participios de presente en nominativo, al funcionar como nominativos absolutos, dieron lugar a frecuentísimos anacolutos, hecho de lengua característico del sermo familiaris y de las lenguas dominadas por elementos afcctivos, como sucede en las habladas. Junto a ello, esta época concede una mayor libertad que en el periodo clásico, facilitada por la tendencia a distanciar el verbo principal; asimismo, sc producen casos frecuentes de sujeto lógico (nominativus pendens) y el nominativo absoluto fue potenciado por los escritores cristianos.

Es, pues, toda una constclación de fenómenos la que propicia la construcción finita del participio de presente. Fntre ellas, el uso «hipertrofiado» del participium coniunctum en los historiógrafos había contribuido decididamente a privarle del valor temporal que poseía en los periodos clásico y postclásico. El análisis del uso de participio de presente asociado al orden de palabras revela que se convierte en una especie de mecanismo estilístico preconcebido consistente en una estructura-tipo narrativa integrada por un verbo principal que desempcña la función đe núcleo, al que se le suman uno o varios participios de presente, antepuestos y postpuestos, que conciertan con el sujeto cn nominativo, de acuerdo con una secuencia cronológica; el participio precede al verbo principal cuando la acción expresada por él es anterior a la del verbo principal: Alem fuvium.. transeuntes, Armeniam, Syriam Ciliciamque, Galatiam, Pisidiam... domuerunt (Jordanes, Geica VI, 51); postpuesto refleja una acción posterior: Theoderidus vero victor existens (1) subactis pepercit (2)... preponens

28 aSe puede hablar, pues, hasta aquí de grecismo en el sentido de que la extensión libre de las construcciones participiales por encima de los límites semántico, estilísticos y estadísticos bastantc estrechos que les asignaba el uso latino, se debió al influjo directo de los textos griegos. Pero es prcciso destacar que más allá de este hecho, los usos no «agramaticales», no son propiamente un grecismo sino una extensión imusitada del empleo del participio de presente latino como expresión alternativa en muchos de nuestros ejemplos de nociones relativas y circunstanciales, nociones que podía comportar desde siempre, aunque el latín anterior explotara menos esta posibilidad, y en cuanto a los casos de agramaticailidad cahe ver también en ellos una parte al menos de desarrollo propio del latín» (Arias, 1999: 200).

29 En ningún caso permiten una explicación general del fenómeno y la forma personal siempre constituye la lectio facilior (Lorenzo, 1998: 46-55). 
(3) Suavis... clientem propium nomine Agrivulfim (Jordanes, Getica XLIV, 233) ${ }^{30}$. A partir de esta estructuras puede entenderse el paso siguiente en el que el participio de presente es el único verbo de la oración (ibid: 40 ):

Qui Theodoricus iam adulescentiae annos contingens expleta pueritia, decem et octo annos peragens, ascitis certis ex satellitibus patris et ex populo amatores sibi clientesque consocians, paene sex milia uiros, cum quibus inconscio patre emenso Damubio super Babai Sarmatarum rege discurrit, qui tunc de Camundo duce Romanorum uictoria potitus superbiae tumore reganabat, eoque (...) (Jordanes, Getica LV, 282)

El participio de presente, por tanto, terminó por convertitse en un recurso comodín, una forma verbal neutra, cuyo valor dependía de la colocación, culminando así cl proceso de valoración de su naturaleza verbal.

En el sermo familiaris, en cambio, con la excepción de la aparición del nominativo absoluto, la estructura de participio de presente quedó totalmente «bloqueada», por lo que no han quedado restos de ella en las lenguas románicas. En palabras de Arias (1999: 204), esto fue debido a que «la tendencia más dominante fue la primacía del funcionamiento nominal (adjetival) del participio y su progresiva sustitución (en su funcionamiento verbal) por el gerundio" y "por la evolución en su conjunto de la subordinación en latín tardío», que tendió a primar las construcciones introducidas por conjunción. Se llega asi a la clasificación de ésta como "vulgarismo escrito» al igual que el si interrogativo directo o las perífrasis de participio de futuro y gerundivo $+\mathrm{sum}^{3 \mathrm{I}}$.

Se consagra así una escisión dentro de los fenómenos del latín vulgar: por un lado, aquellos que contribuyen a la formación de las lenguas románicas y que se asocian a fenómenos evolutivos propios de la lengua; por el otro, aquellas estructuras que sólo aparecen en los textos conservados y que apartadas de la norma clásica no prosperaron en la evolución al romance. Cabrá preguntarse en relación con los autores de tales escritos, ya que su lengua se considera más cercana a la conversación, qué pudo propiciar un alejaniento tan marcado de ésta. Este alejamiento, por otra parte, sin llegar al «divorcio» con la norma hablada que puede intuirse en este caso, constituye un elemento esencial de la escritura latina desde una concepción artistocrática y escolar, como veremos a continuación.

\section{LATINITAS: URDANITAS, ELECANTLA Y ... ESCUELA}

Retornando a los usos del participio de presente latino clásico y postclásico, éstos permiten explicarse desde toda una serie de posibilidades. Ya hemos indicado la importancia de la diacronía y el papcl desempeñado en él por figuras de la talla de Cicerón. Sin embargo, considerarlo exclusivamente un fenómeno cronológico —afirmando, en consecuencia, que la rección sólo se alcanza plenamente cl siglo I a.C.- - deja sin explicación tanto los ejem-

30 Lorenzo, 1998: 45.

31 Arias (1999; 203-205). Herman (1996: 306-7) es el primero en expresar este concepto: «Les faits examinés ont permis de cerner une couche très particulière du système des variétés latines: c'est le «vulgaire» écrit, une variété demilettrée, qui produit dcs innovations en apparente harmonie avec les tendances qui caractérisent l'usage parlé des personnes peu cultivées, mais des innovations qui tiennent surtout compte d'cxigences qui sont celles de l'écrit ou celles de la parole qui s'y rattache. Ces innovations, (...), elles sont nées au niveau de l'écrit et restent surtout à ce nivenu, se bloquent donc facilement sous la pression de processus pius généraux et plus profonds». 
plos de Terencio (siglo II a.C.) como la ausencia de éstos en Séneca (siglo I d.C.) ) $^{32}$ Por esta razón, Marouzeau (1910) analizó las estructuras de participio transitivas y concluyó que se daban especialmente en los historiadores y, sobre todo, en los ce época impcrial. De este modo, la estilística - ligada tanto a autores como a géneros literarios- se sumaba a la evolución cronológica, a la hora de explicar el uso «verbal» del participio de presente.

La mención de Terencio nos permite abordar la siguiente reflexión. No descubriremos nada nuevo si afirmamos que las obras de Plauto, fecundas en ejemplos de participios, sin embargo, raramente ofrecen casos en los que la base léxica haya sido utilizada como elcmento propiciador de una amplificatio de la oración ${ }^{33}$. En consecuencia, deberemos atender a la diferencia que tantas veces se ha señalado entre Plaulo ${ }^{34}$ y Terencio: mientras el primero emplea una lengua cercana a los registros coloquiales, Terencio introduce en sus obras la lengua propia de la aristocracia romana del siglo II a.C. Es este hecho y no otro el que supondrá que, desde muy pronto, Terencio pase a engrosar el canon escolar de los autores latinos ${ }^{35}$, es decir, a ser el primero de los autores que se consideran imprescindibles para conocer la «norma culta latina».

La lengua latina ha sido analizada en no pocas ocasiones como un producto unitario y uniforme a todos los niveles. Si bien el concepto de «dialecto» en relación al latín ha cambiado notablemente a lo largo del siglo $\mathrm{XX}$ y se ha dignificado la existencia de variantes regionales ${ }^{36}$, el análisis histórico sigue mostrando en gran medida ese estado monolítico de la lengua — salvo la excepción evidente del origen de la lengua en el periodo arcaico (especialmente preliterario) y los desarrollos tardíos que anuncian el paso a las lenguas románicas — normalmente considerado dentro del análisis del llamado latín vulgar- No magnificaremos la importancia de las evoluciones que se producen entre el siglo I a.C. y el III d.C., pero el hecho es que se producen por más que la existencia de una «norma» y la estabilidad política alcanzada en torno a la ciudad de Roma constituyan un freno a avances evolutivos de gran calado.

La aristocracia romana había iniciado de modo consciente una «normalización de los textos escritos» desde principios del siglo Il a.C. Terencio debe inchuirse en estos círculos, donde, junto a un fuerte influjo helenístico, se afirmarán los ideales de urbanitas -identificación del uso correcto de la lengua a partir de los usos propios de Roma- y la elegantia - la búsqueda del alejamiento consciente de los usos coloquiales-; ambos ideales tienen como consecuencia la desaparición de todos los rasgos que denotasen antiquitas, claramente sabina, o rusticitas, de tendencia itálica. La suma de todos esos elementos dará lugar a la latinitas que adquiere su formulación definitiva en Varrón y, sobre todo, en Cicerón ${ }^{37}$.

Un ejemplo puede ilustrarnos lo que estamos diciendo. La forma latina dederont $>$ dederunt), tal como ha llegado hasta nosotros es la propia del latín urbano. Junto a ella, la epigrafía suministra las formas siguientes: *dedront (cf. fecront, ILLPR 303; Fucino, s III

\footnotetext{
32 Mellet et alii, 1994: 286-302.

33 Vide Bennett (1910: 429-435) y Lindsay (1907: 78).

34 Los únicos ejemplos que permitiráan que dudásemos de esta afirmación son casos en los que se emplea la perifrasis con cl verbo sim, e.g. postilla obtegere eam neglegens fui (-neglexi) (Plauto, Mostellaria 141) (I.indsay, ibid.).

35 Quintiliano, Inst. Or. I, 8.

36 Díaz y Diaz (1960), Herman (1967), Mayer (1994), Tovar (1986), Väänänen, (1974) o Wuest (1990).

37 Vincis, 1995: 354; Diaz y Díaz, 1951.
} 
a.C.); dedero (ILLPR 129; Preneste, s. III a.C.); dedrot (ILLPR 23; Pesaro, s. II a.C.); dedron (ILLPR 123; Roma, s. II a.C.); dedro (ILLPR 24; Pesaro, s. II a.C.). Como ha explicado Campanile ${ }^{38}$, una visión tradicional de la lengua latina primaría la urbanitas y establecería el siguiente esquema bipartito:

\begin{tabular}{|l|c|c|}
\hline Forma teórica & \multicolumn{2}{|c|}{ dederont } \\
\hline Desarrollos & $\begin{array}{c}\text { urbanitas: } \\
\text { dederont }\end{array}$ & $\begin{array}{c}\text { formas del latino dialectal: } \\
\text { *dedront, dedero, dedrot, } \\
\text { dedron, dedro, etc. }\end{array}$ \\
\hline
\end{tabular}

Sin embargo, la realidad, muy diferente a ese esquema, respondería más bien a un esquema pluripartito como el siguiente:

\begin{tabular}{|l|c|c|c|c|c|c|}
\hline Forma teórica & \multicolumn{5}{|c|}{ dederont } \\
\hline Desarrollos & dederont & ${ }^{*}$ dedront & dedero & dedrot & dedron & dedro \\
\hline
\end{tabular}

Terencio, en nuestra opinión, ejemplifica el intento, más o menos consciente por parte de un grupo influyente de la aristocracia romana, de convertir las situación mostrada en el segundo esquema en la del primero. Sin embargo, en Roma, durante cl siglo II a.C. y los primero años del I a. C., los textos oficiales eran propicios a la inclusión de cualquier forma del latín dialectal, probablemente en un intento no confesado de crear una koiné cn la que pudiesen reconocerse igualmente los ciudadanos quc hablaban un latín dialectal; ahora bien, esta tendencia contrastaba en los hechos con la que se producia en los ambientes literarios, donde la concesión a los módulos dialectales es prácticamente inexistente. Esta situación doble se prolonga hasta el estallido del Bellum Sociale (91-88 a.C.) que acentuará las diferencias entre Roma y los hablantes itálicos, de modo que culminará acentuando la latinitas, es decir, la «norma culta» romana.

Como un elemento más de todo el proceso, las construcciones de participio se enriquecerán de la mano de los autorcs literarios, donde el influjo de los modelos griegos se deja scntir igualmente. Culminado este proceso, el autor culto disponfa de una herramienta muy valiosa para su expresión; su mayor o monor uso corresponderá a sus gustos estilísticos y, por qué no, a ciertas tendencias de género ${ }^{39}$. En esta situación se llegaría hasta finales del siglo II d.C.

La decadencia cultural iniciada en el siglo III d.C. no pudo sino catalizar el proceso de sustitución de esta estructura por otras (proposiciones de relativo, adverbiales o ablativo del gerundio), ya que todo indica que jamás fue realmente productiva en la lengua hablada. De este modo, sólo la enseñanza escolar normativa en medio de un ambiente general de pobreza cultural notable pudo contribuir a su utilización más allá de la elegantia.

38 Campanile (1993: 13-24).

39 Recordemos en este punto la ausencia de estructuras participiales con régimen, i.e. uso verbal de las formas de participio de presente en Séneca, frente al uso constante de Suetonio, como puede observarse con el ejemplo que abría estas páginas. 


\section{PaRTICIPIO MEdiEVAL Y SERMO SCOLASTICUS}

Nuestro planteamiento apunta, por tanto, hacia la definición de esos usos «agramaticales» del participio de presente como (vulgarismos escolares»; en cierto modo, estaríamos ante la consideración de una «hipercorrección» o mejor, un uso abusivo, kamontonado» decía Arias, que convierte lo gramatical en agramatical.

Para entender bien este proceso y el divorcio establecido en él entre la lengua hablada y la escrita es preciso que apuntemos algunas cuestiones sobre la evolución del concepto de norma, de latinitas, y de la evolución de la escuela en el mundo latino.

La diferente concepción de latinitas, cuando se aborda la enseñanza de la lengua, ha sido resumido por Alberte (1991: 55): «Concretamente, micntras para el autor de la Retórica a Herennio la latinitas era un ideal lingüístico basado en normas gramaticales (IV, 17: Latinitas est quae sermonem purum conseruat ab omni uitio remotum. Vitia in sermone... soloecismus et barbarismus), para Cicerón era un estado de lengua basado no en principios gramaticales sino en la norma de la consuetudo y el uso. Era, pues, para este autor un proceso dinámico y abierto a los cambios, puesto que se hallaba vinculado a la evolución social (Or. 159. Brut. 213)». Se contrapone, si se nos permite, una concepción «escolar» en la que prevalece la gramática y sus normas, de carácter necesariamente inmovilista, donde la lengua es patrimonio de unos pocos que transmiten su correcto uso, y una concepción «social», en movimiento, en la que la lengua es patrimonio compartido por todos sus usuarios. La evolución seguida por la escuela no hará otra cosa que acentuar este proceso.

En cuanto al modelo escolar que se seguirá es indudablemente el establecido por Quintiliano en su Institutio oratoria ${ }^{40}$. En ella, Quintiliano adopta en principio el mismo criterio que Cicerón, puesto que «antepondrá el usus a la docirina (Inst. XII, 6, 4: «el uso sin gramática es más importante que la gramática sin el uso») así como el latine loqui al grammatice loquis (Alberte, 1991: 56). Sin embargo, como les ha sucedido a tantos profesores de lengua a lo largo de la historia de la educación, al poner en práctica este principio, la gramática termina imponiéndose y la consuetudo se entiende «no como una norma sociológica sino como una norma gramatical basada en el principio de autoridad y, por tanto, del recte loquis (ibid.).

La «traición» no debería ser tan grave, si admitimos que la auctoritas puede ser comprendida como la selección de los mejores usuarios de la lengua y, en consecuencia, modelos imitables en su uso ${ }^{41}$. Ahora bien, ésta se consuma cuando la gramática se erige en norma y la consuetudo en consensus eruditorum (Quintiliano, Inst. or. I, 6, 45):

Nam ut transeam quemadmodum uulgo imperiti loquantur; tota saepe theatra et omnem circi turbam exclamasse barbare scimus. Ergo consuetudinem sermonis uocabo consensum eruditorum, sicut uituendi consensum bonorum.

40 Roger (1968: 7-8), quien hace referencia a las cscuclas en Galia, si bien con las debidas precauciones puede ampliarse al resto de la Romanin: «L'cnseignement donné dans les écoles de la Gaule reproduisait, dans ses grandes lignes, les plan d'études que Quintilien a tracé dans 1'Institution oratoires.

41 Estc mismo debate volvió a repetirse en el Renacimiento, dondc, dada la ausencia de hablantes naturales de la lengua, el principio de auctoritas fue, si cabe, más crucial (Hinojo, 1994). La tensión entre la concepción dinámica, y la inmovilista y normativa se reprodujo nuevamente con el claro triunfo de la úttima (Núficz, 1991). 
De este modo, en el siglo II d.C. la oposición entrc Latine loqui y grammatice loqui ha quedado eliminada, ya que el primero se ha diferenciado de ex uulgari consuetudine loqui y el segundo garantiza el acceso a la latinitas que el primero encarna. Y en una evolución lógica, los gramáticos de los siglos III y IV d.C. considera que la latinitas, el Latine loqui cs imposible sin que se produzca un aprendizaje escolar ${ }^{42}$.

La disquisición entre los dos aspectos en medio de ambientes culturales de cierta elevación, v.g. los siglos I y II d.C., puede considerarse de carácter teórico y con una correspondencia poco notable en la práctica. Pero, cuando la situación se invierte y la cultura retrocede en cantidad y calidad, la victoria de la concepción normativa sólo contribuye a alcjar la lengua escrita de la lengua hablada. De este modo se arriba al siglo $\mathrm{V}$ en una situación en la que el alejamiento, progresivo en sus inicios, ha llegado a un punto en el que puede hablarse de la existencia de un sermo scolasticus, una lengua que, a decir de Roger (1968: 77), «n'est ni la langue littéraire classique, ni la langue vulgaire, mais un idiome artificiel». La denominación la podemos encontrar en autores del siglo $\mathrm{V}$ como Gcnnade que dice, acerca del obispo de Lyon Euger (De viris illustribus 64): «Scripsit ... de contemptu mundi et saecularis philosophiae epistulam unam scholastico et rationabili sermone». Esta situación se prolongará hasta los siglos XI y XII, cuando, tras el renacimiento carolingio, se produzca una reforma completa de la cnseñanza, del tipo de lengua y sus normas ${ }^{43}$, así como la lengua latina comparta el espacio expresivo con las pujantes lenguas vernáculas.

Por lo tanto, se ha consagrado cn esa época una denominación que evidentemente es empleada para un uso lingüistico que, aprendido en la escuela, resulta extraño para los hablantes contemporáneos, debido a su lejanía del uso habitual. Dentro de este sermo scolasticus pensamos que han de encuadrarse las estructuras de participio a las que nos venimos refiriendo. Así, junto a las múltiples influencias que hemos mencionado anteriormente, la exposición del participio que encontramos en las gramáticas posibilitará que tales usos no scan concebidos como errores graves, probablemente, una vez consolidados sobre todo como rasgo estilístico en textos historiográficos ni lan siquiera como errores.

Un buen número de gramáticas se ciñen a la construcción formal de los parlicipios, a sus figurae, sin atender a su inserción en la frase. Sin embargo, una gramática tan influyente como serán las Institutiones de Prisciano realiza las siguientes precisiones que hoy consideraríamos de índole sintáctica en el libro XI, De participio ${ }^{44}$.

(...) et quod eos sequantur casus, quos et verba, ex quibus nascuntur, el quod verbonm significationes habent et quod pro verbo ponuntur, quorum nihil est suum nominis (XI, 4).

Nec solum per obliquos casus est utile participium, sed eliam per nominativum. diversa enim verba absque coniunctione adiungere non potes, ut 'Iego disco' vel 'doceo discis'

42 La excepción en todo este proceso está servida por los cristianos ( $\Lambda$ lberte, 1991: 62): «Paradójicamente aqueLlos gramáticos mantenedores de la tradición clásica y concretamente de los usos ciceronianos estaban mucho más lejos de los criterios lingibísticos de Cicerón que Agustín, quien basaba la defensa de usos no ciceronianos, como eran los vulgares de su tiempo, sobre el criterio lingüístico de aquél, esto es, sobre principios sociológicos y no sobre principios gramaticalistas $)$. En cierto modo, esta reffexión sigue la tendencia de la «lengua de los cristianos» cn sus primeros siglos; no obstante, tan pronto como se trata de plasmar este principio en una gramática escolar, como la atribuida al propio San Agustín, ésta se tiñe de características normativas y la principal discusión se ciffe a los autores que sirven de modelo, auctoritas.

43 Frova, 1994: 332.

44 I a negrita es nuestra. 
non est dicendum, sed 'lego et disco' vel 'docen et discis': nam hoc proprium est tam transitivorum quam intransitivorum; participum autem si proferas pro aliquo verbo et adiungas ei verbum, bene sine coniunctione profers, ut 'legens disco'pro 'lego et disco' et 'docente me discis' pro 'doceo et discis' (XI, 9).

Et quamvis ab indicativis derivantur verbis participia, potestate tamen et vi significationis omnes continent modos hoc pacto: 'exponens doce' pro 'expone et doce', 'utinam exponens docerem' pro 'utinam exponerem et docerem', 'cum exponens doceam' pro 'cum exponam et doceam', 'exponens docere volo' pro 'exponere et docere volo'. ergo eius obtinet vim modi, cuitus verbo coniungilur; et in hoc quoque quantam habeat cum infinito coniunctionem ostenditur (XI, 11).

ex quo quoque astenditur significatio participii, quod tam nominis quam verbi vim obtinet. quod et hoc pro illis et illa pro hoc ponuntur: dicimus enim 'legens est, qui legit' et 'qui legit, est legens', 'caenatus est, qui caenavit' et 'qui caenavit, caenatus est'(XI, 25).

Como era de esperar, no hemos encontrado en sus líneas una referencia explícita a los usos medievales que analizábamos arriba. No obstante, sí aparece la refercncia a la que aludíamos en el sentido de que subraya el carácter sustitutivo de las formas verbales - se llega a equiparar al pronombre en esta función-y la economía que se consigue en los textos gracias a él, pudiendo evitarse el uso de la conjunciones -i.e. de la subordinación-. Es cste precisamente el aspecto que subraya especialmente Alcuino en su De grammatica, $292^{45}$ :

FR. Quam ufilitatem habet participium in nominativo et vocativo, si sic verbi loco obliquis jungantur? SAXO. Quod verba sine conjunctione in nominativo et vocativo conjungere potes. Nam diversa verba sine conjunctione recti jungi non passunt, ut, lego, scribo; vel doceo, discis, non est dicendum; sed lego et scribo, doceo et discis. Si participium loco prioris verbi ponas, bene sine conjunctione profertur, ut, legens scribo, docens discis.

Las gramáticas, cn consecuencia, siempre que no reduzcan lá exposición del participio a la mínima expresión de sus figurae -i.e. la morfología del participio- se centran en la capacidad que posee para insertarse en la frase en el lugar de un verbo en forma personal. Aún más, su gran utilidad se descubre por la explotación de la anterior propiedad, ya que permite evitar cl uso de las conjunciones tanto de coordinación como de subordinación. Quedaban así sentadas las bases para su uso 'amontonado', fruto de la amplificatio en las oraciones.

\section{CONCLUSIONES}

El participio de presente latino resume en su evolución diacrónica dos oposiciones y los resultados de éstas. La una cs de carácter estrictamente gramatical y la otra sociolingüistica.

La primera consiste en la oposición adjetivo / verbo y ofrece el modo en que, desde unos orígenes estrictamente adjetivales, las formas de participio devienen en verbales por mor de sus aplicaciones estilísticas y cultas. Incluso, tal como hemos visto, llegan a suplantar completamente a la forma verbal finita.

45 La gramática de Alcuino de York reproducc csencialmente las Ars minor y Ars maior de Donato, así como las Instilutiones de Prisciano (Roger, 1968: 336-343). 
Ahora bien, este estadio final sólo se produce dentro de la segunda de las oposiciones, la que opone norma escrita y lengua de uso —especialmente hablada-. Los ejemplos manifiestan que este fenómeno diacrónico sólo es conocido en los textos escritos - incluso con más incidencia en unos géneros literarios que en otros-. En este sentido, debe atcndersc al principio de la elegantia, esencial en la cultura latina escrita, por el que se pretende de modo consciente el extrañamiento de la lengua en los textos que la aleje del registro hablado. Ahora bien, mientras estos principios se rodean de una cultura desarrollada y extendida, de una rica producción literaria y apenas se dejan notar las fuerzas centrífugas que a fines del Imperio iniciarán los pasos hacia las lenguas románicas, la elegantia está encauzada por el equilibrio que posibilita que ambos registros se reconozcan con toda propiedad.

Sólo un uso escolar que se ateja paulatinamente de un dominio directo y clcvado de los mecanismos de la lengua propiciará un uso creciente de las estructuras de participio de presente en la amplificatio de la frase. Ya en el siglo II d.C. en una prosa científica y de escasas pretensiones literarias como la de Suetonio se registra este fenómeno.

Finalmente, la aparición de otros elementos — sustitución de oraciones de relativo, evitación de las subordinadas, profusión en el uso de participios, nominativus pendens o absoluto-, donde la adaptación al latín de los textos cristianos en lengua griega no es de poca importancia, contribuirá decisivamente al desarrollo de lo que, a todas luces, es un vulgarismo escrito y escolar. El latín vulgar y las lenguas romances no conocerán, en absoluto, este uso. Incluso las últimas no emplearán el participio de presente con su naturalcza verbal, i.e. con régimen, salvo en calidad de cultismo.

\section{REFFRFNCIAS BIBLIOGRÁFICAS}

Adam S, J. N. (1973): «THe SUbStantival P ReSENT P ARIICIPIE IN LAINN》, Glotta 51, págs. 116-136. Adrados, Fco. Rodríguez (1975): Lingizística indoeuropea, Madrid.

Alarcos Llorach, E. (1994): Gramática de la Lengua Española, Madrid.

Alberte, A. (1991): «Actitud de los cristianos ante el principio de la latinitas», EClás. 100, págs. 55-62.

Alcántara Martínez, Pedro de (1969): Historia de la lengua ilaliana, 2 vols., Madrid.

Arias Abellán, C. (1999): «Innovaciones en el latín cristiano: participio de presente en lugar de forma persnal del verbo", en Petersmann, H. - Kettemann, R. (eds.), Latin vulgaire - Latin Tardif $V$. Actes du Veme Colloque International sur le latin vulgaire et tardif, Heidelberg, 5-8 septembre 1997, Heidelberg, págs. 195-207.

Bassols de Climent, M. (1956): Sintaxis latina, Madrid.

Battaglia, G. $\left(1974^{10}\right)$ : Gramática latina, Roma.

Bemnett, Ch. E. (1910): Syntax of Early Latin, I: The verb, Boston (reimpr. Hildesheim, 1966).

Bolkestein, A. M. (1976): «AcI and ut-clauses with verba dicendi in Latin», Glotta 54, págs. 263 291.

Bosque, I. - Demonte, V. (dirs.) (1999): Gramática descriptiva de la Lengha Española, Madrid.

Dardano, M. - Trifonc, P. (1985): La lingua italiana, Bologna.

Díaz y Díaz, M. C. (1951): «Laititas. Sobre la evolución de su concepto», Emerita 19, págs. 35-50.

Campanile, E. (1993): «ll latino dialettale», en Campanil e, E. (ed.), Caratteri e diffusiones del Latino in Età Arcaica, Pisa, págs. 13-24.

Coleman, R. (1989): «The Rise and Fall of Absolute Constructions: a Latin Case History», en Calboli, G. (ed.), Subordination and other topics in Latin. Proceedings of the Third Colloquizm on Latin Linguisics (Bologna, 1-5 April 1985), Amsterdam-Philadelphia, págs. 353-374. 
Díaz y Díaz, M. C. (1960a) «E1 latín de la Península Ibérica: dialectalismos», Enciclopedia lingüística hispánica I, Madrid, págs. 237-249.

Díaz y Díaz, M. C. (1960b) «El latín de la península ibérica: rasgos lingüísticos», en Enciclopedia lingüistica hispánica, 1 , Madrid págs. 153-197.

Eklund, S. (1970): The periphrastic, completive and finite use of the present participle in latin, Uppsala.

Fernández Murga, F. (1975): «El participio de presente en italiano y en español. Estudio comparativo», Revista de Filología Moderna, 54, págs. 345-366.

Frova, C. (1994): «Scuole e università», en Cavallo, G. - Leonardi, Cl. - Menesiò, E. (eds.), Lo spazio letterario del Medievo. I. Il Medievo latino. 2. La circolazione del tesio, Roma, págs. 331-360.

Gili y Gaya, S. (1964'): Curso superior de sintaxis española, Barcelona.

Heinc, R. (1990): «Recensie Harm Pinkster: Lateinische Syntax und Semantik», Götingische Gelehrte Anzeigen, 242, págs. 1-14.

Herman, J. (1967): «Les particularités de l'ćvolution du latin provincial», ACILR 12, págs. 125-131.

Herman, J. (1996): «À propos du si interrogatif: ćvolutions achevées et évolutions bloquées», en Bammesberger, A. - Heberlein, Fr. (eds.), Akten des VIII internationalen Kolloquiums zur lateinischen Linguistik, Heidelberg, págs. 296-307.

Hinojo Andrés, Gregorio (1994): «La norma lingüistica en el latín renacentista», cn Actas del VIII Congreso Español de Estudios Clásicos (Madrid, 23 al 28 de septiembre de 1991), Madrid, III, págs. 329-346.

Hofmann, J. B. - Szantyr, A. (1965): Lateinische Syntax und Stilistik, München.

Keil, H. (ed.) (1855): Grammatici Latini, vols. II y III. Prisciani Grammatici Caesariensis Institutiones Grammaticae, ed. M. Hertz, Leipzig (reimpr. Hildesheim - New York, 1981).

Kühner, R. - Stegmann, C. (1912-1914): Ausfïhrliche Grommatik der lateinischen Sprache, II: Satzlehre, Hannover (rev. A. Thierfelder, Leverkusen, 19553; reimpr. Darmstadt, 1982).

Laughton, E. (1964): The parciple in Cicero, Oxford.

Lavency, M. (1997'12): Vsus. Grammaire latine, Louvain-la-Ncuvc.

Lehmann, Ch. (1973): Latein mit abstrakten Strukturen, München.

Lindsay, W. M. (1907): Syntax of Plautus, Oxford.

Lorenzo, J. (1998): «El participio de presente latino: auge y ocaso de una forma verbal», Cuadernos de Filología Clásica. Estudios Latinos 15, págs. 37-58.

Luque Moreno, J. (1978): «El orden de palabras en la doctrina de los gramáticos y rétores latinos», Actas del V Congreso Español de Estudios Clásicos, Madrid, págs. 385-390.

Marouzcau, J. (1910): L'emploi du participe de présent à l'époque républicaine, Paris.

Marouzeau, J. (1922 (I); 1938(II); 1949 (III) y 1953 (compl.)): L'ordre des mots dans la phrase latine, 3 vols. + compl. (L'ordre des mots en latin), Paris.

Mayer y Oliver, M. (1994): «El latín de Hispania», cn Actas del VIII Congreso Español de Estudios Clásicos (Madrid, 23 al 28 de septiembre de 1991), Madrid, págs. 363-382.

Mellet, S. - Joffre, M.-D. - Serbat, G. (1994): Le signifié du verbe, Louvain-Paris.

Mensick, J. A. H. (1994): «The semantic value of restrictive participle clauses in Latin», en Herman, J. (ed.), Linguistic studies on latin. Selected papers from the 6th international colloquitm on latin linguistics, Budapest, 23-27 march 1991, Philadelphia, págs. 241-257.

Núñez González, J. Mª (1991): «Ciceronianismo y latín renacentista», Minerva 5, págs. 229-257.

Pinkster, H. (1995): Sintaxis y semántica del latín, trad. de $\mathrm{M}^{\mathrm{a}}$ E. Torrego y I de la Villa, Madrid (= Latijnse syntaxis en semantiek, Amsterdam, 1984 con adiciones de la ed. ingl., 1990).

R.A.E. (1983): Esbozo de una nueva gramática de la lengua española, Madrid.

Ramat, P. (1994): «On Latin Absolute Constructions», en Herman, J. (ed.), Linguistic Studies on Latin. Selected Papers from the $6^{\text {th }}$ International Colloquium on Latin Linguistics (Budapest, 23-27 March 1991), Amsterdam-Philadelphia, págs. 259-268. 
Roger, M. (1968): L'enseignement des lettres classiques d'Ausone à Alcuin. Introduction à l'histoire des écoles carolingiennes, IIildesheim.

Rubio Fernảndez, L. (1972): «El orden de palabras en latín clásico», Homenaje a A. Tovar, Madrid, págs. 403-423.

Seco, M. - Andrćs, O. - Ramos, G. (1999): Diccionario del español actural, Madrid, 1999.

Serbat, G. (1985): «Adjectif verbal et nom d'action», Vita Latina 98, págs. 18-22.

Serianni, L. (1997): Italiano, 'lorino.

Suetonio (1964): Vida de los doce Césares, vol. I, ed. y trad. M. Bassols de Climent, Barcelona

Suetonio (1992): Vidas de los doce Césares, vol. I, trad. R. Ma. Agudo Cubas, Madrid.

Vega, M. A. (ed.) (1994): Textos ciásicos de teoria de la traducción, Madrid.

Väänänen, V. (1974): «Le problème de la divcrsification du latin», $R E L$ 52, págs. 19-20.

Thurot, Ch. (1869): Extraits de divns manuscrits latins pour servir à l'histoire des doctrines grammaticales au Moyen Age, Paris (reimpr. Frankfurt am Main, 1964).

Tovar, A. (1986): «Estado de la investigación sobre el latín vulgar y sus variantes locales», en Alvar Ezquerra, A. (cd.), Minerva restituta. 9 lecciones de flología clásica, Alcalá de Henares, págs. 109-138.

Vineis, E. (1995): «Latím,, en Ramat, A. G. - Ramat, P. (eds.), Las lenguas indoeuropeas, Madrid (=Bologna, 1993), págs. 347-419.

Woodcock, E. C. (1959): A new latin syntax, London.

Wuest, J. (1990): «Unité du latin ou unification du latin?», en Herman, J. (ed.), Latin vulgaire-latin tardif I (Actes du Ier. Coll. int. sur le latin vulg. et tardif), Tübingen, págs. 235-249.

Zeegers, N. - Vorst, V. (1997): «Les fonctions du participe en grec et en latin», en DE VSV. Études de syntaxe latine offertes à Marius Lavency, Louvain-La-Neuve, págs. 345-364. 